\title{
Effects of iron concentration and redox states on failure of boron-free E-glass fibres under applied stress in different conditions
}

\author{
QINGWEI WANG ${ }^{1,2, *}$, RICHARD K BROW ${ }^{2}$, HONG LI ${ }^{3}$ and ERICA ANN RONCHETTO ${ }^{2}$ \\ ${ }^{1}$ State Key Laboratories for Modification of Chemical Fiber and Polymer Materials, Donghua University, \\ Shanghai 201620, China \\ ${ }^{2}$ Material Research Center, Missouri University of Science and Technology, Rolla 65409, USA \\ ${ }^{3}$ Fiber Glass Science and Technology, PPG Industries Inc., Cheswick 15024, USA \\ *Author for correspondence (wqwq888@dhu.edu.cn)
}

MS received 7 June 2016; accepted 6 September 2016; published online 26 July 2017

\begin{abstract}
Hydrolysis resistance of boron-free E-glass fibre with different total iron oxide $\left(\mathrm{Fe}_{2} \mathrm{O}_{3}\right)$ concentrations, iron redox index and durations of fibre ageing up to 180 days at $50^{\circ} \mathrm{C}$ with $50 \%$ relative humidity $(\mathrm{RH})$ was studied. The effect of ageing on the fibre failure measured in two different test environments was examined by using two-point bending method. Based on the differences in failure strains of the fibres obtained from the two conditions as a function of ageing time, the Griffith theory of solid fracture was applied to estimate glass surface energy difference in ageing conditions. The results showed that stress-assisted hydrolysis, when the fibres were under stress, could lead to about 5.18 times reduction in surface energy to account for 2.30 times reduction in fibre failure strain when tested in 50\% RH at room temperature. Our study showed that the boron-free E-glass aged up to 180 days only deteriorated within $13 \%$, independent of total $\mathrm{Fe}_{2} \mathrm{O}_{3}$ concentration and $\mathrm{FeO} / \mathrm{Fe}_{2} \mathrm{O}_{3}$ total ratio, and stress-assisted hydrolysis played a key role during sample testing. Dynamic fatigue of the aged E-glass fibres was also investigated, showing little influence of total $\mathrm{Fe}_{2} \mathrm{O}_{3}$ concentration and $\mathrm{FeO} / \mathrm{Fe}_{2} \mathrm{O}_{3}$ total ratio on fibre stress; corrosion susceptibility was observed.
\end{abstract}

Keywords. Iron oxide; ageing; failure strain; surface energy; hydrolysis; glass fibre.

\section{Introduction}

E-glass fibres are most widely used in the reinforcement of plastic materials in composite applications [1]. Raw materials used to produce E-glass fibres, such as kaolinite, sand, limestone, dolomite, etc., often contain iron oxide $\left(\mathrm{Fe}_{2} \mathrm{O}_{3}\right)$ as an impurity. Very often, the concentration of $\mathrm{Fe}_{2} \mathrm{O}_{3}$ is adjusted in the E-glass batch, depending on the difference between the concentration of $\mathrm{Fe}_{2} \mathrm{O}_{3}$ intended for the glass by design and the total $\mathrm{Fe}_{2} \mathrm{O}_{3}$ contributed by the impurities in the raw material, to maintain stability of both total $\mathrm{Fe}_{2} \mathrm{O}_{3}$ concentration and ratio of ferrous to ferric ion $\left(\mathrm{Fe}^{2+} / \mathrm{Fe}^{3+}\right.$ or $\left.\mathrm{Fe}^{2+} / \mathrm{Fe}_{\text {total }}\right)$ in the glass. Controlling their stabilities is critical for fibre drawing process. In general, higher $\mathrm{Fe}^{2+}$ concentration in glass or higher $\mathrm{Fe}^{2+} / \mathrm{Fe}_{\text {total }}$ ratio leads to faster cooling of fibre during the attenuation process, with diameter reduction by more than two orders of magnitude from the time the melt exits the bushing tips to the final fibre solidification. This results in higher fibre drawing tension, which can break the fibres. On the other hand, if $\mathrm{Fe}^{2+} / \mathrm{Fe}_{\text {total }}$ becomes too low and fibres cannot be cooled within less than a fraction of second, the fibre forming cone becomes too large to cause bridge formation between adjacent fibres, resulting in fibre breakage and flooding of the bushing [1]. Besides the requirement of stable $\mathrm{Fe}^{2+} / \mathrm{Fe}_{\text {total }}$ ratio for fibre drawing process, an important question related to composite applications is whether there is any impact, beneficial or negative, on the E-glass fibre tensile strength when the total $\mathrm{Fe}_{2} \mathrm{O}_{3}$ concentration and/or $\mathrm{Fe}^{2+} / \mathrm{Fe}_{\text {total }}$ ratio varies.

Numerous studies have been done to understand the roles of ferrous and ferric ions in silicate glasses [2,3]. The dissolution reaction of iron oxides in molten silicate glass is governed by the equation $\left[\mathrm{Fe}_{2} \mathrm{O}_{3}\right]+\left[\mathrm{O}^{2-}\right] \leftrightarrow 2\left[\mathrm{FeO}_{2}\right]^{-}$depending on the temperature, oxygen partial pressure of the melt and external pressure (constant for commercial glass melting). A widely accepted understanding is that ferrous ion $\left(\mathrm{Fe}^{2+}\right.$ or $\mathrm{FeO}$ ) functions as a modifier, depolymerizing the glass network and ferric ion $\left(\mathrm{Fe}^{3+}\right.$ or $\left.\mathrm{Fe}_{2} \mathrm{O}_{3}\right)$ functions, in general, as a network former, polymerizing the glass network, similar to $\mathrm{Al}_{2} \mathrm{O}_{3}$ but to a lesser degree [4]. Supporting evidence can be found based on the effect of iron redox ratio on melt viscosity of silicate glasses, which shows that the melt viscosity at a given temperature increases as $\mathrm{Fe}^{3+}$ concentration in the $\mathrm{Fe}^{3+} / \mathrm{Fe}_{\text {total }}$ ratio increases [4,5]. Fundamental understanding of the effect of iron concentration and iron redox ratio on the mechanical properties of the fibre is critically needed to guide new product development and associated economics of fibre glass making, including control of batch material costs (allowing higher impurity iron concentration 
in the raw material generally leads to lower purchasing costs of the materials).

To the best of our knowledge, there are few studies in the literature on the effect of iron redox ratios on the mechanical properties of the glass fibres. In the study of E-glass fibres by McKinnis [6], the concept of stress-degrading melt defects (MDs) was introduced. The MD concentration was shown to be inversely proportional to fibre tensile strength; in addition, fibres derived from more reduced melts contained higher levels of MD, and hence, lower tensile strength than fibres from more oxidized melt. However, the actual iron redox values of the glasses, both reduced and oxidized, were not reported; therefore, it is difficult to quantitatively assess the impact of redox reactions on fibre tensile strength. Effects of total iron concentration and iron redox ratios on the tensile strength of stone wool fibres were reported in Lund et al [7]. The tensile strength of the wool fibres was shown to increase proportionally with the $\mathrm{Fe}^{3+} / \mathrm{Fe}_{\text {total }}$ ratio. The study showed that the calculated concentrations of bridging oxygen in the glasses were linearly proportional to $\mathrm{Fe}^{3+} / \mathrm{Fe}_{\text {total }}$ ratio, supporting the argument that ferric ion functions as a glass network former, and hence, improves the fibre strength. On the basis of the compositions studied [7], it is difficult to separate the effects due to main oxide variations (for example, 40.0-52.4\% $\quad \mathrm{SiO}_{2}, 14.4-20.7 \% \quad \mathrm{Al}_{2} \mathrm{O}_{3}, 1.0-12.9 \%$ $\mathrm{Fe}_{2} \mathrm{O}_{3}, 0.4-2.1 \% \mathrm{TiO}_{2}$, etc. $)$ and iron redox variations $\left(\mathrm{Fe}^{2+} /\right.$ $\mathrm{Fe}_{\text {total }}$ ratio of $\left.0.18-0.97\right)$.

The motivation for our iron redox study (IRS) was to address whether for E-glass, the total iron concentration or its redox ratio, or both, have a significant influence on the mechanical properties of the fibre. To minimize the effects of other glass constituents, including boron and fluorine, which have high volatility in batch melting, we have chosen a single, boron and fluorine-free E-glass as the host composition. The host glass composition was then systematically modified by changing the total iron concentration, starting with $\mathrm{Fe}_{2} \mathrm{O}_{3}$, with and without oxidizing and reducing agents. To determine the effects of iron redox ratio or total iron concentration on fibre strength, we performed a set of glass fibre mechanical tests under liquid nitrogen to eliminate the moisture effect in addition to testing glass fibres under a constant, controlled humidity condition.

\section{Experimental}

\subsection{Fibre sample preparation}

The E-glass cullet samples were provided by PPG Industries Inc. for this study [8]. The baseline E-glass contained (wt\%) $61.0 \mathrm{SiO}_{2}, 13.5 \mathrm{Al}_{2} \mathrm{O}_{3}, 20.5 \mathrm{CaO}, 4.6 \mathrm{MgO}$ and $0.2\left(\mathrm{Na}_{2} \mathrm{O}+\mathrm{K}_{2} \mathrm{O}\right)$. Table 1 summarizes the concentrations (values obtained by $\mathrm{X}$-ray fluorescence in parentheses) of the glasses with singly doped and/or co-doped $\mathrm{Fe}_{2} \mathrm{O}_{3}, \mathrm{MnO}_{2}, \mathrm{SnO}_{2}$ and $\mathrm{CeO}_{2}$. The glasses can be characterized into two groups. In the first group of IRS 1-4, the
Table 1. Nominal and measured concentrations (wt \%) of total iron and of oxidizing/reducing agents in the baseline E-glass samples.

\begin{tabular}{lcccc}
\hline No. & $\mathrm{Fe}_{2} \mathrm{O}_{3}+\mathrm{FeO}$ & $\mathrm{MnO}_{2}$ & $\mathrm{SnO}_{2}$ & $\mathrm{CeO}_{2}$ \\
\hline IRS 1 & $0.02(0.03)$ & 0 & 0 & 0 \\
IRS 2 & $0.22(0.21)$ & 0 & 0 & 0 \\
IRS 3 & $0.40(0.41)$ & 0 & 0 & 0 \\
IRS 4 & $0.64(0.65)$ & 0 & 0 & 0 \\
IRS 5 & $0.46(0.46)$ & $0.42(0.36)$ & 0 & 0 \\
IRS 6 & $0.46(0.45)$ & 0 & $0.48(0.42)$ & 0 \\
IRS 7 & $0.46(0.45)$ & 0 & 0 & $0.60(0.30)$ \\
\hline
\end{tabular}

Note: All values in parentheses were measured by XRF; and XRF measured $\mathrm{MnO}_{2}$ and $\mathrm{SnO}_{2}$ concentrations in the singly $\mathrm{Fe}_{2} \mathrm{O}_{3}$-doped glasses were not greater than $0.002 \mathrm{wt} \%$ for in all cases and no detectable $\mathrm{CeO}_{2}$ was present in all glasses without $\mathrm{CeO}_{2}$ doping.

host glass composition was systematically doped with $\mathrm{Fe}_{2} \mathrm{O}_{3}$ up to $0.64 \mathrm{wt} \%$, while in the second group of IRS 5-7, the host glass doped with $0.46 \mathrm{wt} \% \mathrm{Fe}_{2} \mathrm{O}_{3}$ was further modified by adding two oxidizing agents $\left(\mathrm{MnO}_{2}\right.$ and $\left.\mathrm{CeO}_{2}\right)$ and one reducing agent $\left(\mathrm{SnO}_{2}\right)$ separately.

Cullet samples of a given composition were prepared from $1000 \mathrm{~g}$ melts in a platinum crucible at $1500^{\circ} \mathrm{C}$ for $4 \mathrm{~h}$ (melt viscosity was less than $10 \mathrm{~Pa} \mathrm{~S}$, based on viscosity measurement), followed by a quick air cooling of the melt on a steel plate. In the preparation of fibre samples used in this study, each glass cullet was re-melted in a platinum crucible at $1550^{\circ} \mathrm{C}$ for $8 \mathrm{~h}$ for better melt homogenization prior to fibre drawing. The melt was immediately transferred to another furnace preset at $1300^{\circ} \mathrm{C}$ for $60 \mathrm{~min}$ for conditioning. Each glass melt was drawn into fibres using a vertical up-draw system at $1300^{\circ} \mathrm{C}$. Fibres were wound onto a rotating cage, which was designed to prevent the contact damage of the fibres by overlaying on top of each other. The fibre diameter was controlled by the pulling temperature and the rotating speed of the cage. Fibres in the diameter range of 100-200 $\mu \mathrm{m}$ were prepared under ambient conditions. These pristine glass fibres were immediately placed in a humidity and temperature-controlled oven for ageing treatment.

\subsection{Fibre ageing treatment}

All fibres were aged in an environmental chamber at $50^{\circ} \mathrm{C}$ and under $80 \%$ relative humidity $(\mathrm{RH})$ for various lengths of time, ranging from 1 day up to 7 months. During the treatment, at a given time, a set of minimum 20 fibres per composition per ageing time was periodically taken out of the chamber for testing, leaving the others in the chamber without physical disturbance.

\subsection{Fibre failure measurement by using two-point bending method}

The effect of ageing on the failure characteristics of glass fibres with different total iron concentrations and iron redox 
ratios was studied by using the two-point bending (TPB) technique to determine the maximum strain on the fibre at failure. The test procedure using the two-point fibre bending apparatus (TNL Tool and Technology, LLC, Parnell, IA) has been described in detail elsewhere $[9,10]$. For aged fibres, the TPB tests were performed under two conditions, namely, in ambient air at room temperature $\left(22 \pm 1^{\circ} \mathrm{C}\right)$ at a $\mathrm{RH}$ of $50 \pm 1 \%$ ('wet') and in liquid nitrogen at $-196^{\circ} \mathrm{C}$ ('dry'). In this way, both the effect of ageing and that of moisture in the testing environment on fibre fracture can be determined separately. For each set of experimental conditions, a minimum of 20 fibres were used to determine its average strain at failure and to perform Weibull statistical analysis [11].

\subsection{Spectroscopic characterizations}

An ultraviolet-visible (UV-Vis) spectrophotometer (Thermo Scientific Genesys 10S UV-Vis) was used to determine the $\mathrm{Fe}^{2+}$ absorption over the visible range to quantify the relative differences of the glasses with different total iron concentrations and with and without addition of oxidizing or reducing agent.

Scanning electron microscope (SEM) (FEI Helios NanoLab 600 FIB) coupled with Oxford energy dispersive spectrometer (EDS) were selectively used to characterize fibre surface morphology and near surface composition.

\section{Results}

\subsection{Effect of total iron concentration and of oxidizing and reducing agents on final glass iron redox values}

Figure 1 shows UV-Vis spectra of the glasses with different total iron concentrations and iron redox ratios as prepared. The band that peaked at $1065 \mathrm{~nm}$ is a characteristic absorption band of the ferrous ion and is shown to be linearly proportional to total $\mathrm{Fe}_{2} \mathrm{O}_{3}$ in the glass (insert in figure 1); this implies that independent of total $\mathrm{Fe}_{2} \mathrm{O}_{3}$ in the glass, the iron redox ratio reached equilibrium between $\mathrm{FeO}$ and $\mathrm{Fe}_{2} \mathrm{O}_{3}$. It shows that the iron redox ratio or $\mathrm{FeO} / \mathrm{Fe}_{2} \mathrm{O}_{3}$ total ratio was constant for IRS 1-4, although $\mathrm{FeO}$ concentration was shown to increase as the total $\mathrm{Fe}_{2} \mathrm{O}_{3}$ concentration in the glass sample increased. At a fixed $\mathrm{Fe}_{2} \mathrm{O}_{3}$ level $(0.46 \mathrm{wt} \%)$, the $\mathrm{Fe}^{2+}$ concentration in both $\mathrm{MnO}_{2}$ and $\mathrm{CeO}_{2}$-doped glasses (IRS 5 and 7) was lower; whereas in $\mathrm{SnO}_{2}$-doped glass (IRS 6), it was higher than the expected value, without using either oxidizing $\left(\mathrm{MnO}_{2}\right.$ and $\left.\mathrm{CeO}_{2}\right)$ or reducing $\left(\mathrm{SnO}_{2}\right)$ agents. It is to be further noted that $\mathrm{CeO}_{2}$ has higher oxidizing power than $\mathrm{MnO}_{2}$. The concentrations of $\mathrm{FeO}$ or total $\mathrm{Fe}_{2} \mathrm{O}_{3}$ for all samples calculated by $\mathrm{UV}-\mathrm{Vis}$ spectra are presented in table 2 .

\subsection{Effect of total iron concentration and iron redox ratio on failure strain of fibres without ageing}

The TPB method samples fibre surface defect(s) very close to the centre point of the fibre bending, where the fibre surface experiences the highest tensile stress. The population of defects in a specific location can be different than that distributed through the entire surface of the fibre under uniform tensile stress. Therefore, we compared the fibre failure strain determined by TPB using the methods depicted in figure $2 \mathrm{a}$ and $b$, instead of performing Weibull statistical analysis. For pristine fibres with different iron concentrations and iron redox tested at $22^{\circ} \mathrm{C}$ and $50 \% \mathrm{RH}$, the average failure strains were similar, within $0.5 \%$ of the overall average of $6 \%$ (figure $2 \mathrm{a}$ ). On the other hand, among IRS 1 to 4, IRS 4, with the highest total $\mathrm{Fe}_{2} \mathrm{O}_{3}$ and highest $\mathrm{FeO}$ concentration (table 2), seemed to have slightly lower failure strain. For the co-doped

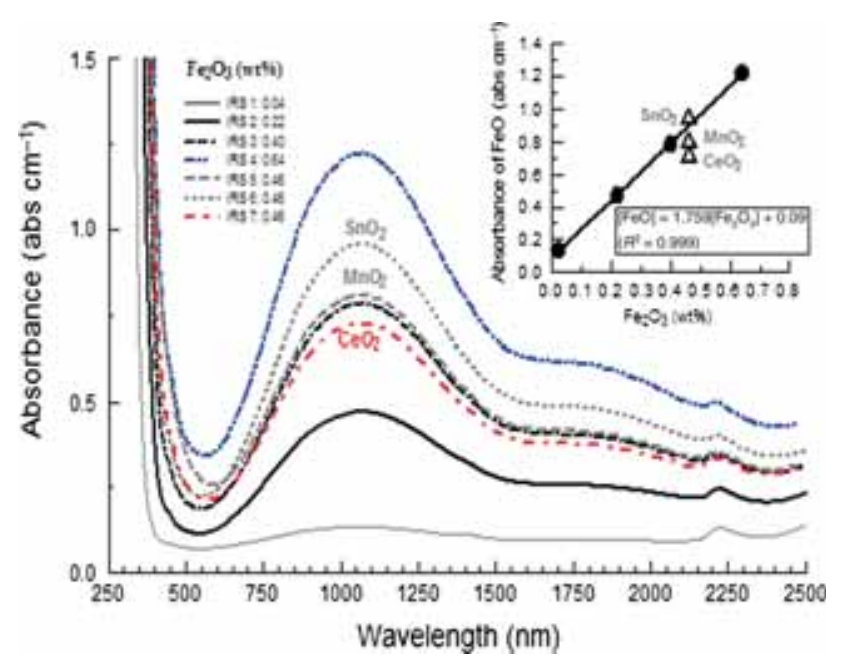

Figure 1. UV-Vis spectra of glasses with various total iron concentrations and iron redox ratios illustrating ferrous ion absorption near wavelength of about $1010 \mathrm{~nm}$.

Table 2. FeO concentrations and $\mathrm{FeO} / \mathrm{Fe}_{2} \mathrm{O}_{3}$ total ratio for the seven samples measured by UV-Vis spectra.

\begin{tabular}{lccccccc}
\hline & IRS 1 & IRS 2 & IRS 3 & IRS 4 & IRS 5 & IRS 6 & IRS 7 \\
\hline Fe total (wt\%) & 0.04 & 0.20 & 0.4 & 0.64 & 0.46 & 0.46 & 0.46 \\
$\mathrm{FeO}($ wt\%) & 0.02 & 0.08 & 0.13 & 0.21 & 0.14 & 0.16 & 0.12 \\
$\mathrm{Fe}^{2+} / \mathrm{Fe}_{\text {total }}(\%)$ & 50.0 & 40.0 & 32.5 & 32.8 & 30.4 & 34.8 & 26.1 \\
\hline
\end{tabular}



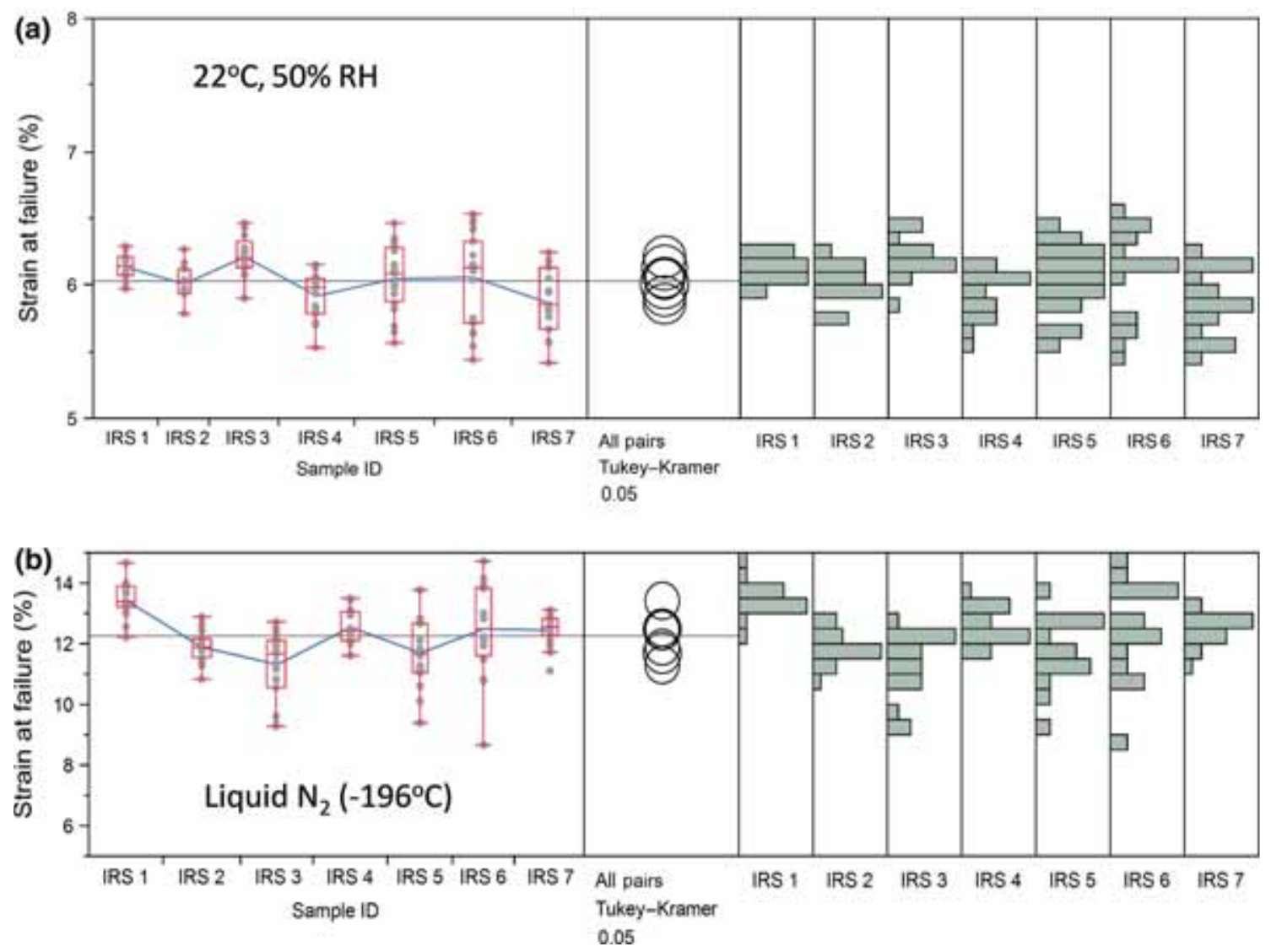

Figure 2. Pristine fibre failure strain determined under conditions of (a) $22^{\circ} \mathrm{C}$ and $50 \% \mathrm{RH}$ and (b) liquid nitrogen at $-196^{\circ} \mathrm{C}$ (left, box plot and line of average value; mid, compare mean; and right, histogram of each set).

glasses with either oxidizing or reducing agent (IRS 5-7), distribution of the failure strain appeared to be wider than singly doped glass fibres. Although the difference was small, IRS 7 fibres co-doped with $\mathrm{CeO}_{2}$ likely had the lowest average failure strain among all glass fibres. For the same set of fibres without ageing, when tested in liquid nitrogen, their perspective average failure strain significantly increased, nearly two times against their counterpart tested with $50 \% \mathrm{RH}$; their grand average of strain failure was about $12 \%$ (figure $2 \mathrm{~b}$ ). However, there existed a clear trend that the average failure strain decreased with total $\mathrm{Fe}_{2} \mathrm{O}_{3}$ concentration from 0.04 to $0.40 \mathrm{wt} \%$ (IRS $1-3$ ) by as much as $2 \%$ and then 'recovered' at a higher total $\mathrm{Fe}_{2} \mathrm{O}_{3}$ concentration of $0.64 \%$ (IRS 4) as well as at $0.46 \%$ with $\mathrm{MnO}_{2}, \mathrm{SnO}_{2}$ and $\mathrm{CeO}_{2}$ (IRS 5-7), as depicted in figure $2 \mathrm{~b}$. When comparing with liquid nitrogen test data, the effect of moisture on weakening fibres or increasing fibre failure strains was clearly demonstrated. A more detailed study will be discussed next.

\subsection{Effects of ageing on failure of fibres with different total $\mathrm{Fe}_{2} \mathrm{O}_{3}$ concentration or $\mathrm{FeO} / \mathrm{Fe}_{2} \mathrm{O}_{3 \text { total }}$ ratio}

3.3a Fibre failure in humid condition: Failure strains of glass fibres with different total $\mathrm{Fe}_{2} \mathrm{O}_{3}$ concentrations and
$\mathrm{FeO} / \mathrm{Fe}_{2} \mathrm{O}_{3 \text { total }}$ ratios (IRS 1-4) were plotted as a function of ageing time in figure 3. The TPB tests were performed at $22^{\circ} \mathrm{C}$ with a controlled RH of $50 \%$. Approximately $13 \%$ of deteriorations of fibre failure strain was found, most of which took place during the first 7 days of the ageing treatment.

It was noticed that IRS 1, with the lowest total $\mathrm{Fe}_{2} \mathrm{O}_{3}$ and hence the lowest $\mathrm{FeO}$, exhibited slightly higher average failure strains over the entire period of fibre ageing up to 180 days than the rest of glass fibres. In addition, it was noted that with a slight increase in iron doping, IRS 2 with $0.22 \mathrm{wt} \% \mathrm{Fe}_{2} \mathrm{O}_{3}$ exhibited the lowest failure strains after the first 7-day ageing, whereas fibres with 0.40 and $0.64 \mathrm{wt} \% \mathrm{Fe}_{2} \mathrm{O}_{3}$ (IRS 3 and 4) showed some 'recovery', both of which have similar failure strains between IRS 1 and 2 over the rest of ageing time. The iron concentration appears to have an effect on the ability of a fibre to resist hydrolysis, although the initial pristine fibre failure strains were more or less the same (figure 1).

Figure 4 illustrates failure strains of the aged fibres with nearly the same total $\mathrm{Fe}_{2} \mathrm{O}_{3}$ concentration but different $\mathrm{FeO} / \mathrm{Fe}_{2} \mathrm{O}_{3 \text { total }}$ ratio as a function of ageing time up to 180 days. A similar trend was found in this case, where the ageing effect was the most pronounced during the first 7 days, as seen in other singly doped glasses without oxidizing or reducing agents. Among IRS 4-7, within the error range of 


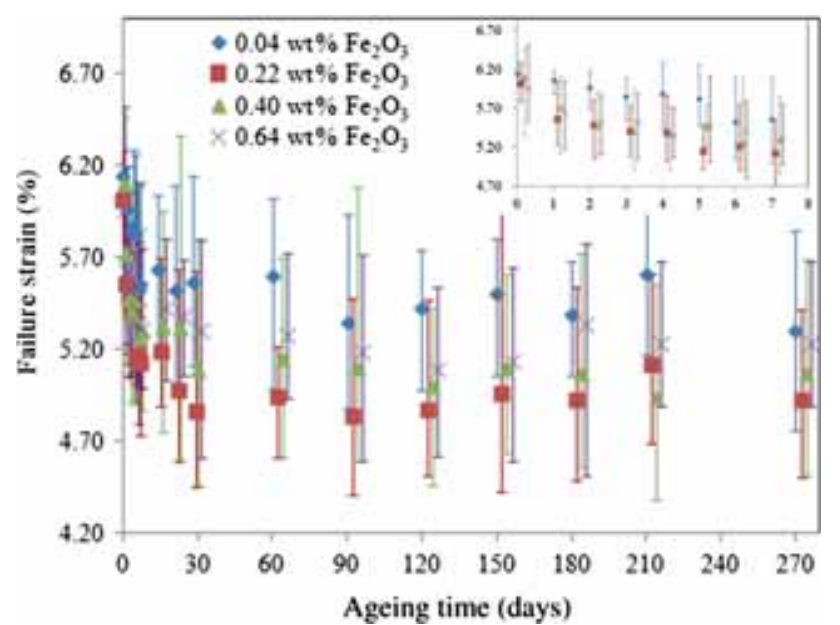

Figure 3. Failure strain in ambient condition (at $22^{\circ} \mathrm{C}$ with $50 \%$ $\mathrm{RH})$ for the aged glass fibres with different total iron concentrations and the same redox ratio as a function of ageing time (the data points represent average value from 20 measurements; for clarity purpose, the average data points and error bars were artificially shifted along the $x$-axis).

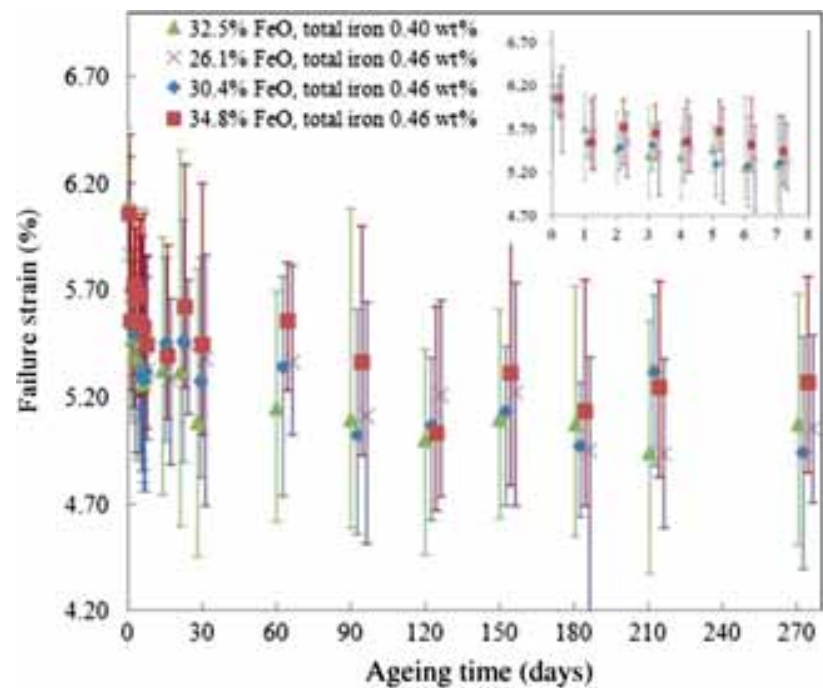

Figure 4. Failure strain in ambient condition (at $22^{\circ} \mathrm{C}$ with $50 \%$ $\mathrm{RH}$ ) for the aged glass fibres with different redox ratios as a function of ageing time (the data points represent average value from 20 measurements; for clarity purpose, the average data points and error bars were artificially shifted along the $x$-axis).

the measurements, all the fibres appear to have statistically the same average failure strain for a given ageing time.

In summary, for fibres aged for more than 30 days, it appeared that fibre resistance to ageing was ranked as follows: IRS 1 > IRS 3 and IRS 4 > IRS 2; whereas IRS 5-7 behaved similar to IRS 3. Overall, over a range of $\mathrm{Fe}_{2} \mathrm{O}_{3}$ concentration or $\mathrm{FeO} / \mathrm{Fe}_{2} \mathrm{O}_{3 \text { total }}$ ratio, all the aged E-glass fibres reduced their failure strains within $13 \%$, compared to their pristine fibre counterparts.

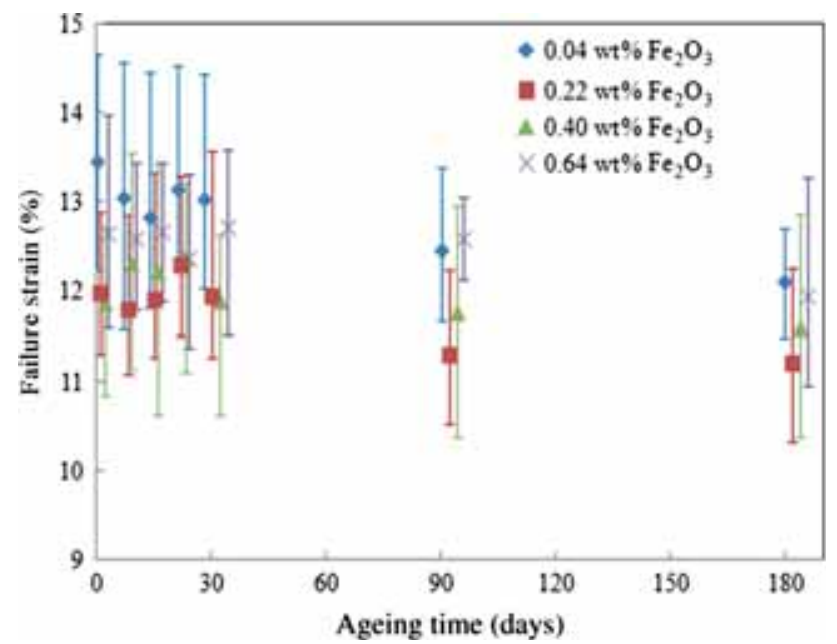

Figure 5. Failure strains of the fibres measured by the TPB method in liquid nitrogen $\left(-196^{\circ} \mathrm{C}\right)$ for the aged glass fibres with different total $\mathrm{Fe}_{2} \mathrm{O}_{3}$ (the data points represent average value from 20 measurements; for clarity purpose, the average data points and error bars were artificially shifted along the $x$-axis).

3.3b Fibre failure under liquid nitrogen condition: The mechanical tests described above showed the combined effect of both fibre ageing and humidity of the test condition for each glass type. To minimize the effect of humidity during the tests on fibre failure strain, we performed a new set of tests by immersing fibre sample and test apparatus in liquid nitrogen at $-196^{\circ} \mathrm{C}$ to remove moisture around the fibre surfaces using the previous aged fibres (IRS 1-4). Figures 5 and 6 exhibit the failure strain on the aged fibres that were stressed in the absence of moisture or in 'dry' conditions. Performing fibre tests in liquid nitrogen was more difficult than that in ambient air, which might explain much higher data scattering shown in figure 4 , as compared with those in figure 6 . Based on the resolution of the TPB test method, statistically, it is not unreasonable to conclude that all the fibres experience similar average failure strain during a short 7-day ageing treatment. For fibres aged greater than 30 days, fibre resistance to ageing ranked as follows: IRS 1, IRS $4>$ IRS $3>$ IRS 2; whereas IRS 5-7 behaved similar to IRS 3. Overall, in terms of effects of total $\mathrm{Fe}_{2} \mathrm{O}_{3}$ or $\mathrm{FeO}$ concentration or $\mathrm{FeO} / \mathrm{Fe}_{2} \mathrm{O}_{3 \text { total }}$ ratio, failure strains of all the E-glass fibres varied slightly within $13 \%$, compared to their pristine fibre counterparts. It implies that fibre mechanical deterioration by pre-hydrolysis remained the same, independent of test conditions 'wet' or 'dry'.

Under both 'wet' and 'dry' test conditions, the results from our study suggested that the baseline E-glass composition with $0.22 \% \mathrm{Fe}_{2} \mathrm{O}_{3}$ had the lowest resistance against ageing at elevated temperature $\left(80^{\circ} \mathrm{C}\right)$ under $50 \% \mathrm{RH}$. That being said, over the entire range of $\mathrm{Fe}_{2} \mathrm{O}_{3}$ concentrations and $\mathrm{FeO} / \mathrm{Fe}_{2} \mathrm{O}_{3 \text { total }}$ ratios, the fibre resistance to ageing was more or less similar. Finally, failure of boron-free E-glass fibres was due to the presence of moisture around the fibres under stress; 


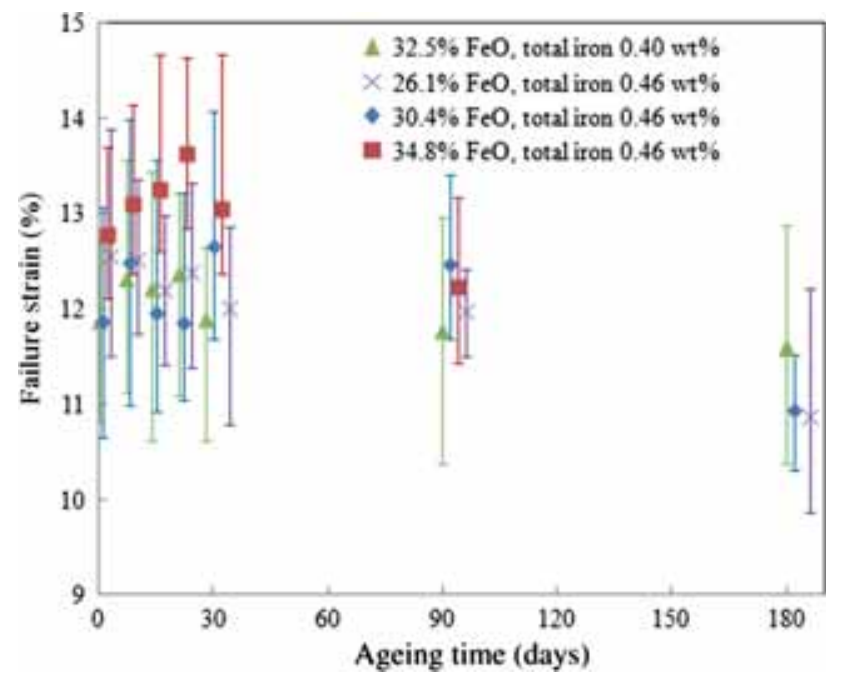

Figure 6. Failure strains of the fibres measured by the TPB method in liquid nitrogen $\left(-196^{\circ} \mathrm{C}\right)$ for the aged glass fibres with different redox ratios (the data points represent average value from 20 measurements; for clarity purpose, the average data points and error bars were artificially shifted along the $x$-axis).

fibres failed at two times higher strain in the 'dry' condition as compared with cases in the 'wet' condition.

3.3c Dynamic fatigue examination of fibres with different total $\mathrm{Fe}_{2} \mathrm{O}_{3}$ : Knowing significantly lower failure strain of the fibres tested under 'wet' conditions, we conducted additional tests to determine if there were any effects of the test duration, after the bending of the fibres, on their final failure strain, i.e., whether any significant fatigue took place when the fibres were stressed slowly or quickly. Such response by the fibre to the rate of the applied stress is termed as dynamic fatigue. In the TPB test, we performed the dynamic fatigue test by using the velocity of the faceplate in the experiments, from which one can deduce the dynamic fatigue parameter, $n[12,13]$

$$
1 /(1+n)=d\left[\log \left(\varepsilon_{\mathrm{f}}\right)\right] / d\left[\log \left(V_{\mathrm{fp}}\right)\right]
$$

where $\varepsilon_{\mathrm{f}}$ is the fibre failure strain and $V_{\mathrm{fp}}$ is the faceplate velocity.

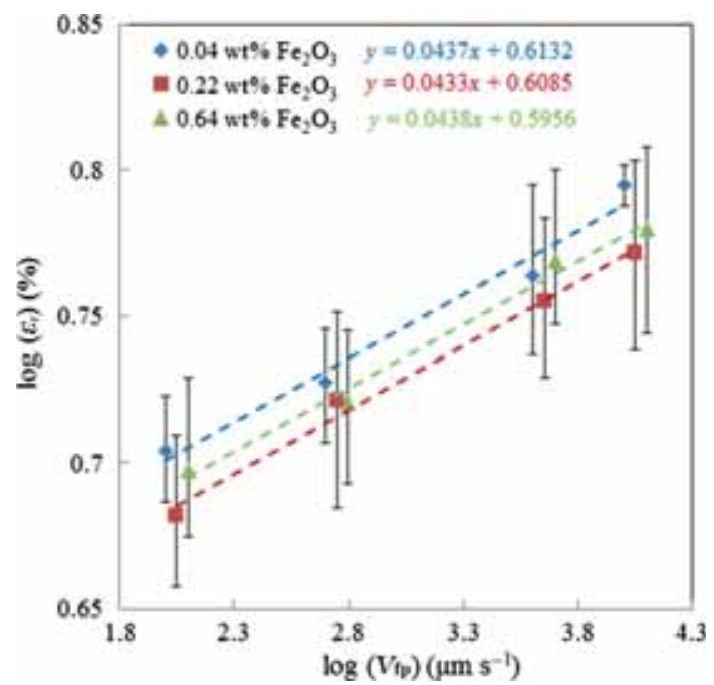

Figure 7. Failure strains measured at ambient condition as a function of faceplate velocity for E-glass fibres with different contents of iron oxide (the data points represent average value from 20 measurements; for clarity purpose, the average data points and error bars were artificially shifted along the $x$-axis).

Figure 7 shows the relationship between the fibre failure strains and the faceplate velocities in a $\log -\log$ scale for the 1-month-aged fibres with different levels of $\mathrm{Fe}_{2} \mathrm{O}_{3}$ concentrations or $\mathrm{FeO} / \mathrm{Fe}_{2} \mathrm{O}_{3 \text { total }}$ ratios (IRS 1, 2 and 4). The $n$-values were deduced from the slopes of lines produced by using linear least-squared regression method (equation 1). Table 3 summarizes the detailed results from the dynamic fatigue study. The faceplate speed range spanned two orders of magnitude. On the basis of the analysis, we found that three sets of aged fibres have similar sensitivity to fatigue based on the $n$-value.

\subsection{Fibre surface characterization}

Fibre surface morphology after 1 month ageing was examined using scanning electron microscopy, as illustrated in figure 8. Similar to pristine fibres, the aged fibres exhibit microscopically smooth surface quality without any physical micro-cracks, except for the existence of a 'shadow pattern'. Comparing with the pristine fibres having surfaces devoid of

Table 3. Failure strain in different faceplate velocities of glass fibres aged for 30 days and the fitted fatigue parameters.

\begin{tabular}{lllllll}
\hline & \multicolumn{4}{c}{ Failure strain in different faceplate velocities (\%) } & & \multicolumn{2}{c}{$\begin{array}{c}\text { Failure strain at } \\
\mathrm{Fe}_{2} \mathrm{O}_{3} \mathrm{wt} \%\end{array}$} & $100 \mu \mathrm{m} \mathrm{s}^{-1}$ & $500 \mu \mathrm{m} \mathrm{s}^{-1}$ & $4000 \mu \mathrm{m} \mathrm{s}^{-1}$ & $10,000 \mu \mathrm{m} \mathrm{s}^{-1}$ & Fatigue parameters, $n$ & $1 \mu \mathrm{m} \mathrm{s}^{-1}$ speed, $\%^{1}$ \\
\hline 0.04 & $5.06 \pm 0.21$ & $5.34 \pm 0.22$ & $5.78 \pm 0.42$ & $6.16 \pm 0.10$ & $23.88 \pm 2.52$ & $4.10 \pm 0.21$ \\
0.22 & $4.81 \pm 0.31$ & $5.27 \pm 0.38$ & $5.69 \pm 0.31$ & $5.91 \pm 0.43$ & $23.83 \pm 1.95$ & $3.96 \pm 0.28$ \\
0.64 & $4.98 \pm 0.25$ & $5.26 \pm 0.31$ & $5.88 \pm 0.29$ & $6.21 \pm 0.21$ & $21.62 \pm 4.70$ & $3.95 \pm 0.22$ \\
\hline
\end{tabular}



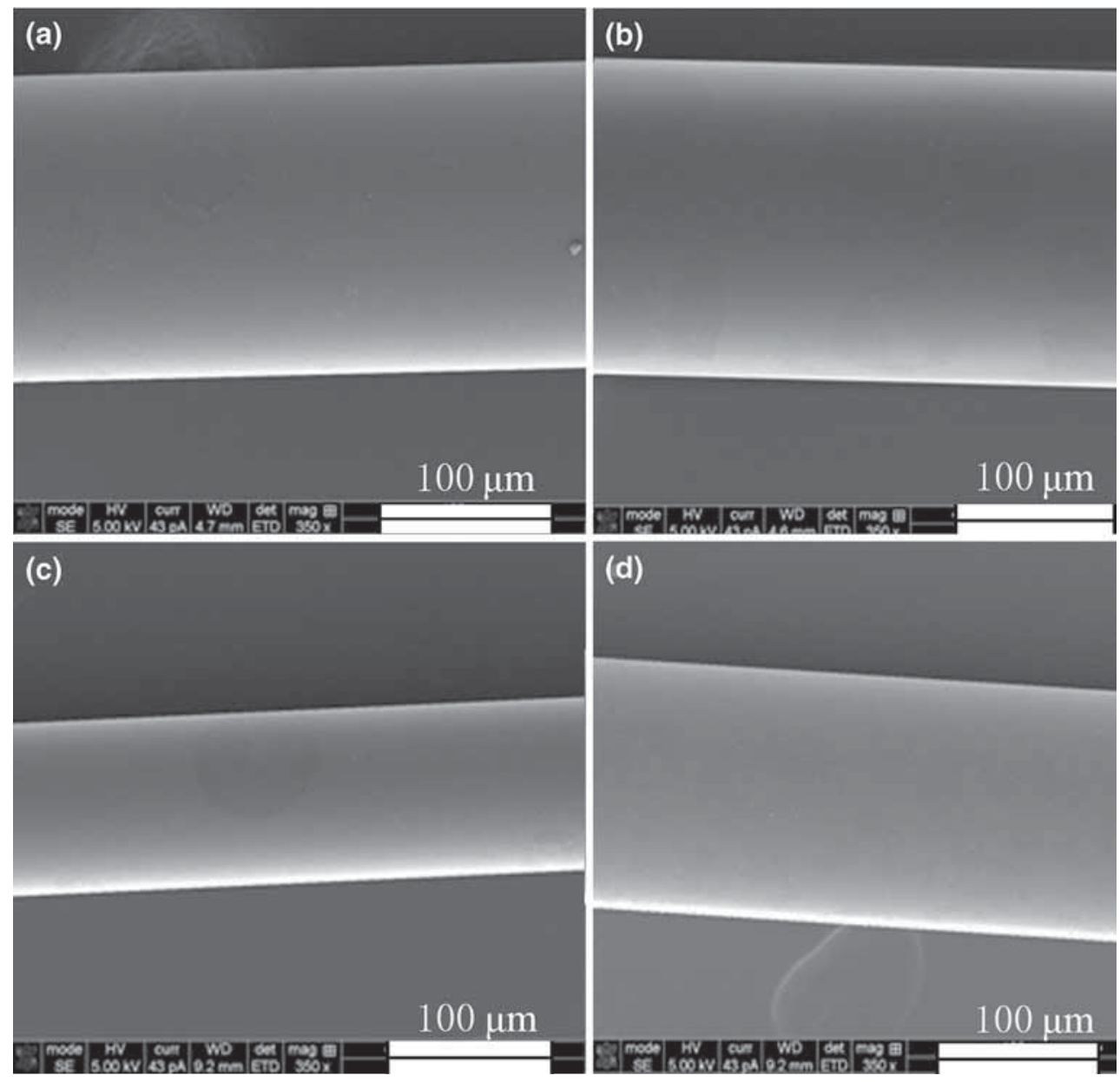

Figure 8. SEM micrographs of E-glass fibres after 1 month ageing at $50^{\circ} \mathrm{C}$ and $80 \% \mathrm{RH}$. (a) IRS 1 with 0.04 wt $\% \mathrm{Fe}_{2} \mathrm{O}_{3}$; (b) IRS 4 with 0.64 wt $\% \mathrm{Fe}_{2} \mathrm{O}_{3}$; (c) IRS 5 with 0.46 wt $\% \mathrm{Fe}_{2} \mathrm{O}_{3}$ and 0.42 wt $\% \mathrm{MnO}_{2}$; and (d) IRS 6 with 0.46 wt $\% \mathrm{Fe}_{2} \mathrm{O}_{3}$ and $0.48 \mathrm{wt} \% \mathrm{SnO}_{2}$.

such patterns, it is possible to say that the local small shadows were related to some sort of local moisture condensation taking place during the ageing treatment. It is, however, very difficult to quantify its distributions as a function of ageing time. Furthermore, due to the nature of TPB method, it is also uncertain whether the critical surface flaw at the maximum tensile stress is directly co-located with the shadow area. Nevertheless, increase in the population of 'shadow pattern' as the ageing treatment progresses is undoubtedly due to increased defect density, leading to higher probability of fibre failure during the TPB tests.

\section{Discussion}

Comparing the results from the TPB tests in the 'wet' and 'dry' conditions, this study showed that moisture on the surface of the fibres played a dominant role in fibre failure due to hydrolysis reactions with the glass structure. It follows that the kinetics of stress-assisted hydrolysis should not be significantly affected by the pre-existing hydration history (up to 180 days). The TPB results on pristine and aged fibres tested in air and under liquid nitrogen demonstrate that stress-assisted hydrolysis plays a dominant role in fibre failure. Surface hydrolysis that occurs during ageing creates some damage sites that initially reduce failure strains, but hydroxyl groups $(\mathrm{Si}-\mathrm{OH})$ that would form on the glass surfaces during ageing do not significantly affect the sensitivity of the fibres to dynamic fatigue. Instead, the hydrolysis of bonds by water at the front of a surface flaw during the TPB test has the greatest effect on failure.

The mechanism of glass fatigue in a humid environment was proposed and experimentally demonstrated by Hillig and Charles [14] and by Wiederhorn [15,16]. The stress-assisted hydrolysis of the glass near the tip of surface flaws can result in significant surface energy $(\gamma)$ reduction. For example, quartz crystals change in surface energy by as much as 10 times with and without hydration [17-20]. Structure of crystalline quartz and fused quartz glass is different; in dry liquid nitrogen, 


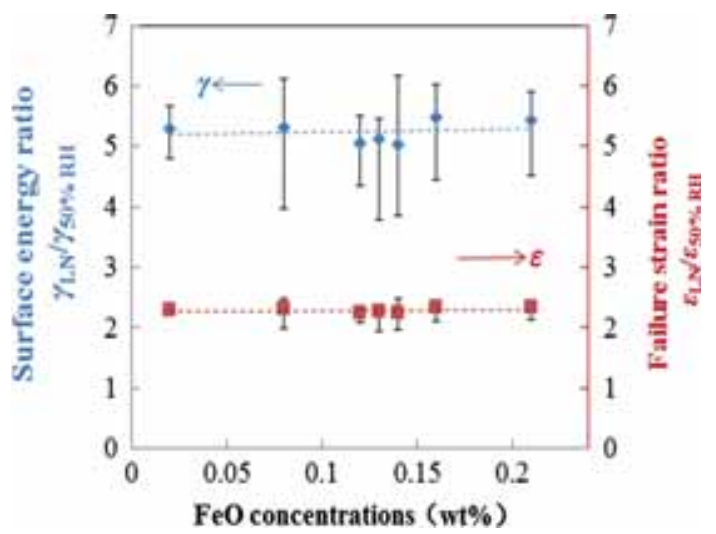

Figure 9. Surface energy ratio, $\gamma_{\mathrm{LN}} / \gamma_{50 \% \mathrm{RH}}$ and failure strain $\varepsilon_{\mathrm{LN}} / \varepsilon_{50 \% \mathrm{RH}}$ deduced from the TPB tests for the aged glass fibres (up to 180 days) as a function of $\mathrm{FeO}$.

their respective ratio is about $0.43\left(2.0 \mathrm{~J} \mathrm{~m}^{-2}\right.$ for crystalline quartz over $4.6 \mathrm{~J} \mathrm{~m}^{-2}$ for fused quartz glass) [21]. In addition, the respective changes in their surface energy, in response to hydration, are expected to follow the same trend [22]. Therefore, the IRS glass fibres tested should also become much weaker under ambient conditions in liquid nitrogen. Assuming all physical surface flaws to be the same in length, $c$, for the fibres under our investigation, according to Griffith theory of fracture mechanics, we can estimate the ratio of the surface energy as $\gamma(\mathrm{LN}) / \gamma(50 \% \mathrm{RH})$, for all cases, which can be derived according to the equation [23]

$$
\sigma_{\mathrm{f}}=E \varepsilon_{\mathrm{f}}=(2 E \gamma / \pi c)^{1 / 2},
$$

where $\gamma$ is the surface energy and $E$ is the fibre modulus being considered as a strain-dependent variable because of large strain experienced by the fibre using TPB method, i.e., Secant Modulus, according to Gupta and Kurkjian [24].

Figure 9 shows the calculated surface energy ratio as a function of $\mathrm{FeO}$ in glass for IRS 1-7 glass fibres with and without ageing up to 180 days. For a given glass or $\mathrm{FeO}$ or total $\mathrm{Fe}_{2} \mathrm{O}_{3}$ concentration, the ratio varies within $15 \%$ of its average, which reflects mostly from the combined variability from the TPB results in 'wet' and 'dry' conditions. Overall, the grand mean was 5.18, with one standard deviation of 0.18 . These results imply that the stress-aided hydrolysis or the mobile molecular water can significantly reduce surface energy at the tip of surface flaw by as much as 5 times, which equates to about 2.3 times reduction in failure strain.

\section{Conclusion}

Hydrolysis resistance of boron-free E-glass fibre was studied by varying total $\mathrm{Fe}_{2} \mathrm{O}_{3}$ concentration, iron redox ratio $\left(\mathrm{FeO} / \mathrm{Fe}_{2} \mathrm{O}_{3 \text { total }}\right)$ and duration of fibre ageing up to 180 days at $50{ }^{\circ} \mathrm{C}$ with $50 \% \mathrm{RH}$. Effect of ageing on fibre failure was examined by using the TPB method, measuring strain of fibre at failure in both 'wet' and 'dry' conditions. Under both test conditions, there seemed to exist a local minimum in fibre resistance to ageing, i.e., fibres with $0.22 \mathrm{wt} \% \mathrm{Fe}_{2} \mathrm{O}_{3}$ had the lowest failure strains over 180 days of ageing treatment at $50^{\circ} \mathrm{C}$ and $50 \% \mathrm{RH}$, whereas fibres with lower or higher $\mathrm{Fe}_{2} \mathrm{O}_{3}$ concentration exhibited slightly higher failure strains. Independent of total $\mathrm{Fe}_{2} \mathrm{O}_{3}$ concentration and iron redox ratio $\left(\mathrm{FeO} / \mathrm{Fe}_{2} \mathrm{O}_{3 \text { total }}\right)$, the most significant mechanical degradation of the fibres took place in the first 7 days of ageing. Based on the differences in failure strains of the fibres tested under the 'wet' and 'dry' conditions, the Griffith theory of solid fracture was applied to estimate glass surface energy difference in both test conditions. The finding implied that stress-assisted hydrolysis, when the fibres are under stress, could result in about 5 times reduction in surface energy to account for 2.3 times reduction in fibre failure strain when tested in 50\% RH at room temperature. Our study showed that the failure strains of the boron-free E-glass aged up to 180 days only deteriorated by $13 \%$, independent of total $\mathrm{Fe}_{2} \mathrm{O}_{3}$ concentration and $\mathrm{FeO} / \mathrm{Fe}_{2} \mathrm{O}_{3 \text { total }}$ ratio, and that stress-assisted hydrolysis during the sample testing played a key role. Dynamic fatigue of the aged E-glass fibres was also investigated, showing little influence of total $\mathrm{Fe}_{2} \mathrm{O}_{3}$ concentration and $\mathrm{FeO} / \mathrm{Fe}_{2} \mathrm{O}_{3 \text { total }}$ ratio on fibre stress; corrosion susceptibility was observed.

\section{Acknowledgements}

The authors appreciate the PPG industries Inc. for funding this research, as well as the financial support from the China Scholarship Council (Grant No. 201306635001).

\section{References}

[1] Li H, Richards C and Watson J 2014 Int. J. Appl. Glass Sci. 5 65

[2] Mysen B O and Richet P 2005 Silicate glasses and melts, developments in geochemistry Ch. 10-11 Vol. 10 (Amsterdam: Elsevier) p 291

[3] Parmar R, Kundu R S, Punia R et al 2014 Physica B 45039

[4] Klein L C, Fasano B V and Wu J M 1983 J. Geophys. Res. 88 880

[5] Dingwell D B and Virgo D 1987 Geochim. Cosmochim. Acta 51 195

[6] McKinnis C L 1986 J. Non-Cryst. Solids 84381

[7] Lund M D, Yue Y Z and Lybye D 2010 Glass Technol. Part A 5197

[8] Li H, Gu P, Watson J and Meng J 2013 J. Mater. Sci. 483075

[9] Tang Z and Brow R K 2014 Int. J. Appl. Glass Sci. 5287

[10] France P W, Paradine M J, Reeve M H and Newns G R 1980 J. Mater. Sci. 15825

[11] Trantina G G 1979 J. Am. Ceram. Soc. 62377

[12] Rondinella V V and Matthewson M J 1993 J. Am. Ceram. Soc. 76139

[13] Wang Q W, Brow R K, Li H and Ronchetto E A 2016 J. Mater. Sci. 512404 
[14] Hillig W B and Charles R J 1965 High strength materials V F Zackey (ed) (New York: John Wiley and Sons Inc.)

[15] Wiederhorn S M 1967 J. Am. Ceram. Soc. 50407

[16] Wiederhorn S M and Bolz L H 1970 J. Am. Ceram. Soc. 53 543

[17] Whalen J W 1961 J. Phys. Chem. 651676

[18] Whalen J W 1961 Adv. Chem. Ser. 33281
[19] Parks G A 1984 J. Geophys. Res. 893997

[20] Kronenberg A K 1994 Rev. Mineral. Geochem. 29124

[21] Wiederhorn S M 1969 J. Am. Ceram. Soc. 5299

[22] Shchipalov Y K 2000 Glass Ceram. 57374

[23] Griffith A A 1924 Proceedings of the first international congress for applied mechanics delft $\mathrm{p} 55$

[24] Gupta P K and Kurkjian C R 2005 J. Non-Cryst. Solids 351 2324 